\title{
RESPOSTA DO FEIJÃO-CAUPI À INOCULAÇÃO DE Bradyrhizobium japonicum, ADUBAÇÃO NITROGENADA E NITROGÊNIO DO SOLO
}

\author{
Willian Nogueira de Sousa'; Nayane Fonseca Brito²; lanna Bizerra Barros ${ }^{3}$; João Thiago Rodrigues \\ de Sousa ${ }^{4}$; Eliandra de Freitas Sia ${ }^{5}$; lolanda Maria Soares Reis ${ }^{6}$. \\ ${ }^{1}$ Universidade Federal do Oeste do Pará, Santarém, Pará, Brasil, wnsagro@gmail.com \\ 2 Universidade Federal do Oeste do Pará, Santarém, Pará, Brasil, nayanebrito4@gmail.com \\ ${ }^{3}$ Universidade Federal do Oeste do Pará, Santarém, Pará, Brasil, nanda_kristina@hotmail.com \\ ${ }^{4}$ Universidade Federal de Viçosa, Minas Gerais, Brasil, iannabb@hotmail.com \\ ${ }^{5}$ Universidade Federal do Oeste do Pará, Santarém, Pará, Brasil, eliandra.sia@hotmail.com \\ ${ }^{6}$ Universidade Federal do Oeste do Pará, Santarém, Pará, Brasil, thiagronomo@yahoo.com.br \\ 7 Universidade Federal do Oeste do Pará, Santarém, Pará, Brasil, iolandareis@outlook.com
}

RESUMO: O feijão-caupi é uma importante cultura agrícola, apresenta capacidade de associação com bactérias que fixam o nitrogênio atmosférico, podendo reduzir custos com fertilizantes. O objetivo no trabalho foi avaliar a produtividade e crescimento de feijão-caupi submetidos à inoculação de bactérias fixadora de nitrogênio (Bradyrhizobium japonicum), adubação nitrogenada e nitrogênio do solo. O experimento foi desenvolvido na Universidade Federal do Oeste do Pará, campus Santarém-Pará, nos meses de abril a julho de 2017, sob viveiro de mudas, em vasos, em delineamento inteiramente casualizado, com nove tratamentos de cinco repetições cada. Os tratamentos foram: uso de inoculante, adubação nitrogenada e nitrogênio do solo e três tipos de feijão-caupi, Manteiguinha, IPA 207 e BRS Tumucumaque, as variáveis avaliadas foram, diâmetro do caule (DC), comprimento de planta (CP), número de grãos por vagem ( $N G)$ e produtividade por hectare $(P G)$. Não houve diferença significativa para as variáveis $D C, C P, N G$ e PG. O Manteiguinha apresentou maiores valores de CP e PG, que foi 1869,5 kg ha-1 quando submetido à adubação nitrogenada. O IPA 207 apresentou menor PG quando inoculada e maior PG com o uso da adubação nitrogenada que foi $2586,1 \mathrm{~kg} \mathrm{ha}^{-1}$. Para o BRS Tumucumaque maior CP foram obtidos no tratamento que usou o nitrogênio do solo, no entanto nesse tratamento a PG foi a menor entre os tratamentos, maior produtividade foi obtido pelo uso da inoculação que foi de 2499, $9 \mathrm{~kg} \mathrm{ha}^{-1}$. A inoculação de Bradyrhizobium japonicum é eficiente para BRS Tumucumaque e ineficiente para IPA 207 em relação à produtividade.

PALAVRAS-CHAVE: Fixação biológica de nitrogênio, Fertilidade, Produtividade.

\section{COWPEA RESPONSES TO THE Bradyrhizobium japonicum INOCULATION, NITROGEN FERTILIZATION AND SOIL NITROGEN}

ABSTRACT: Cowpea bean is an important agricultural crop, which has a high capacity 
of to associate with bacteria that fixes atmospheric nitrogen, which can reduce costs with fertilizers. The objective of this study was to evaluate the productivity and growth rates of cowpea when submitted to nitrogen-fixing bacteria (Bradyrhizobium japonicum), nitrogen fertilization and soil nitrogen. The experiment took place at the Federal University of the West of Pará, Campus Santarém-Pará, during the months of April to July 2017, under greenhouse, in pots, in a completely randomized design, with nine treatments of five replicates each. The treatments were: inoculant use, nitrogen fertilization and soil nitrogen and three types of cowpea, Manteiguinha, IPA 207 and BRS Tumucumaque, the variables evaluated were stem diameter (DC), plant length $(\mathrm{CP})$, number of grains per pod (NG) and productivity per hectare (PG). There was no significant difference for the variables DC, CP, NG and PG. Manteiguinha showed higher values of CP and PG, which was $1869.5 \mathrm{~kg} \mathrm{ha}^{-1}$ when submitted to nitrogen fertilization. The IPA 207 presented lower PG when inoculated and higher PG with the use of nitrogen fertilization, which was $2586.1 \mathrm{~kg} \mathrm{ha}^{-1}$. For the BRS Tumucumaque, higher CP were obtained in the treatment that used the nitrogen of the soil, nevertheless in this treatment the PG was the smaller among the treatments, higher productivity was obtained by the inoculation that was of $2499.9 \mathrm{~kg} \mathrm{ha-1}$. The inoculation of Bradyrhizobium japonicum is efficient for BRS Tumucumaque and inefficient for IPA 207 in relation to productivity.

KEYWORDS: Biological fixation of nitrogen, Fertility, Productivity.

\section{RESPUESTAS DE FRIJOL CAUPÍ A LA INOCULACIÓN DE Bradyrhizobium japonicum, FERTILIZACIÓN NITROGENADA Y PRESENCIA DE NITRÓGENO EN EL SUELO}

RESUMEN: El frijol-caupi es una cultura de importancia económica y social, posee la capacidad de asociación con bacterias que fijan el nitrógeno atmosférico pudiendo reducir costos con fertilizantes. Así, el presente trabajo tuvo como objetivo evaluar la productividad y crecimiento de frijol-caupi sometidos a la inoculación de bacterias fijadora de nitrógeno (Bradyrhizobium japonicum), fertilización nitrogenada y nitrógeno del suelo. Instalado en casa de vegetación, en macetas, el experimento con delineamiento completamente casualizado compuesto por cinco repeticiones de cada tratamiento. Los tratamientos fueron constituidos del uso de inoculante, fertilización nitrogenada y nitrógeno del suelo y tres tipos de frijol-caupí, una variedad (Manteiguinha) y dos cultivares comerciales (IPA 207 y BRS Tumucumaque), se obtuvieron datos de diámetro del caule (DC), longitud de planta (CP), número de granos por vaina (NG) y productividad por hectárea (PG). No hubo diferencia significativa en las variables DC, CP, NG y PG. La variedad Manteiguinha presentó mayores valores de CP y PG, que fue $1869,5 \mathrm{~kg} \mathrm{ha}^{-1}$ cuando sometido a la fertilización 
nitrogenada. La cultivar IPA 207 presentó menor PG cuando inoculada y mayor PG con el uso de la fertilización nitrogenada que fue 2586,1 kg ha ${ }^{-1}$. Para la cultivación BRS Tumucumaque mayor CP fueron obtenidos en el tratamiento que usó el nitrógeno del suelo, sin embargo en ese tratamiento la PG fue la menor entre los tratamientos, mayor productividad fue obtenida por el uso de la inoculación que fue de 2499,9 kg ha-1. La inoculación de Bradyrhizobium japonicum es eficiente en la cultivación BRS Tumucumaque e ineficiente en la cultivación de la IPA 207 en relación a la productividad.

PALABRAS CLAVE: Fijación biológica del nitrógeno, Fertilidad, Productividad.

O feijão-caupi (Vigna unguiculada (L.) Walp.) nos últimos anos, tem gerado o interesse de agricultores de médio e grande porte, e por isso tem se expandido para demais regiões do país. Além de importância alimentar, o feijãocaupi tem alto potencial para adubação verde, por apresentar algumas das características como: rápido crescimento inicial, produção de biomassa, acúmulo de nitrogênio na parte aérea, fácil adaptação, possibilidade de uso para alimentação animal além do elevado potencial de fixação biologia de nitrogênio (ALMEIDA, 2007).

A manutenção ou elevação da produtividade das culturas depende de fatores bióticos e abióticos que podem ser controlados até certo limite. Sendo o suprimento adequado de nutrientes um dos fatores determinante. A fixação biológica de nitrogênio tem se mostrado indispensável para a sustentabilidade da agricultura brasileira, haja vista o fornecimento de nitrogênio às culturas com baixo custo econômico e impacto ambiental reduzido (HUNGRIA et al., 2007).

O nitrogênio é um dos macronutrintes amplamente utilizados nos cultivos agrícolas, e que eleva os custos de produção. O feijão-caupi é capaz utilizar o nitrogênio atmosférico através da associação com bactérias do gênero Bradyrhizobium, no qual estudos comprovam a eficiência simbiótica de algumas estirpes (ZILLI et al., 2006). 
Os benefícios mais representativos são notáveis na cultura da soja, com economia por volta de 6,6 bilhões de dólares por safra (HUNGRIA et al., 2007), reduzindo impactos ambientais ocasionados por fertilizantes lançados ao solo.

Devido aos benefícios que a fixação biológica de nitrogênio pode trazer, o presente trabalho teve como objetivo avaliar a eficiência do uso de inoculante (Bradyrhizobium japonicum BR 3262) em relação a adubação nitrogenada e o nitrogênio do solo na produtividade de duas cultivares e uma variedade de feijão-caupi.

O experimento foi desenvolvido na Universidade Federal do Oeste do Pará, - Campus Tapajós, localizada na cidade de Santarém-PA, sob as coordenadas geográficas $02^{\circ} 24^{\prime} 52^{\prime \prime}$ S e $54^{\circ} 42^{\prime} 36^{\prime \prime} \mathrm{W}$ , município de Santarém-PA. O clima de Santarém segundo a classificação Köppen enquadra-se no tipo climático Am, sendo equatorial úmido com uma estação seca bem definida e outra com índices pluviométricos elevados (ANDRADE et al., 2013). A temperatura média anual varia de $25^{\circ}$ a $28^{\circ} \mathrm{C}$, com umidade relativa do ar média de $86 \%$, a precipitação pluvial média anual é de até 1920mm., com média anual de 2282,6 mm (SILVA et al., 2016).

O experimento foi implantado em viveiro coberto por tela tipo sombrite a $50 \%$, durante os meses de abril a julho de 2017, sua condução ocorreu em vasos com capacidade de 5 litros. O delineamento experimental foi inteiramente casualizado, os tratamentos foram constituídos de uma variedade feijão caupi regional (Manteiguinha) e duas cultivares comerciais (IPA 207 e BRS Tumucumaque), submetidos à inoculação, adubação nitrogenada e ao nitrogênio do solo, com 5 repetições de cada tratamento. $\mathrm{O}$ inoculante utilizado foi estirpes de Bradyrhizobium japonicum (BR 3262), foi utilizado como substrato um Latossolo Amarelo de textura argilosa predominante na região. Foi coletadas amostras desse solo e encaminhado para análises químicas (Tabela 1). 
Tabela 1. Caracterização química e granulométrica do solo.

\begin{tabular}{|c|c|c|c|c|c|c|c|c|c|c|c|c|}
\hline \multicolumn{2}{|c|}{$\mathrm{pH}$} & $P$ & K & $\mathrm{Ca}+\mathrm{Mg}$ & $\mathrm{Ca}$ & $\mathrm{Mg}$ & $\mathrm{Al}$ & $\mathrm{H}$ & CTC & Areia & Silte & Argila \\
\hline \multirow[t]{2}{*}{ Água } & $\mathrm{CaCl}_{2}$ & \multicolumn{2}{|c|}{$m g d m^{-3}$} & \multicolumn{6}{|c|}{ 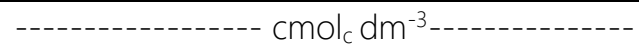 } & \multicolumn{3}{|c|}{------------g/Kg------ } \\
\hline & & & & \multicolumn{6}{|c|}{----- } & \multicolumn{3}{|c|}{---- } \\
\hline 5,4 & 4,7 & 3,3 & 28,8 & 2,8 & 2,0 & 0,7 & 0,3 & 5,0 & 8,1 & 156,0 & 175,0 & 669,0 \\
\hline
\end{tabular}

Foi realizado a correção da acidez do solo aos 40 dias antes da implantação da cultura, conforme recomendações EMBRAPA (2007). Antes do plantio, realizou-se a desinfecção das sementes do feijãocaupi, imergindo-as em álcool a 100\% por 30 segundos e hipoclorito de sódio a 2,0\% por 3 minutos e 10 lavagens sucessivas com água destilada esterilizada As sementes passaram por desinfecção em álcool 70\% por 30 segundos, depois em hipoclorito de sódio a 2\% por 3 minutos, e seguido de 10 lavagens sucessivas em agua esterilizada (ARAUJO; GUALTER, 2017), posteriormente as sementes foram inoculadas 4 horas antes do plantio com estirpes de Bradyrhizobium japonicum (BR 3262) com proporção de $5 \mathrm{~g}$ do inoculante para cada $500 \mathrm{~g}$ de sementes, utilizando-se uma solução açucarada a 10\% (30 g de açúcar em 300 ml de água) para melhor aderência do inóculo.

A complementação da adubação potássica, fosfatada e nitrogenada (esta ultima apenas no seu respectivo tratamento) foram realizadas de acordo com EMBRAPA (2007), levando em consideração os teores obtidos na analise de solo.

Foram coletados dados de número de grãos por vagem, diâmetro do caule a base do solo e comprimento de plantas aos 97 dias após emergência, e produtividade de grãos estimada em $\mathrm{kg} \mathrm{ha-1}$. A umidade de grãos foi corrigida a $15 \%$ conforme as Regras para Analises de Sementes (MAPA, 2009). Os resultados foram submetidos a analise de variância e as medias dos tratamentos comparados pelo teste Tukey a 5\% de probabilidade. 
As variáveis número de grãos tratamento em que utilizou adubação vagem, diâmetro do caule e nitrogenada, seguido da inoculação comprimento de planta não sofreram com Bradyrhizobium japonicum (BR influências significativas dos 3262) e nitrogênio do solo, com tratamentos aplicados neste exceção na cultivar IPA 207, em que a experimento (Tabela 2).Em relação ao inoculação apresentou valores número de grãos por vagem, valores menores que o nitrogênio do solo. maiores foram encontrados no

Tabela 2. Valores médios de $N^{\circ}$ de grãos por vagem, diâmetro do caule e comprimento de plantas, submetidos aos tratamentos; adubação nitrogenada (NA), inoculação (IN) e nitrogênio do solo (NS).

\begin{tabular}{|c|c|c|c|}
\hline Tratamento & No grãos/vagem & $\begin{array}{l}\text { Diâmetro caule } \\
(\mathrm{mm})\end{array}$ & $\begin{array}{l}\text { Comp. Planta } \\
\text { (cm) }\end{array}$ \\
\hline & \multicolumn{3}{|c|}{ 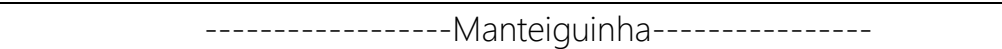 } \\
\hline IN & $13,9 a b$ & $8,4 \mathrm{a}$ & 182,2 a \\
\hline AN & $14 a b$ & $7,7 \mathrm{a}$ & 188,9 a \\
\hline \multirow[t]{2}{*}{ NS } & $13,4 a b$ & 8,3 a & 183,2 a \\
\hline & \multicolumn{3}{|c|}{ 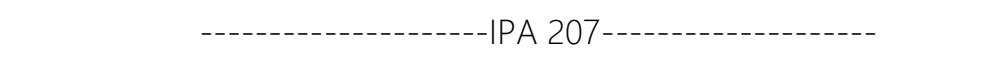 } \\
\hline IN & 14,6 a & $7,6 \mathrm{a}$ & $191,4 \mathrm{a}$ \\
\hline AN & $15,2 \mathrm{a}$ & $7,5 \mathrm{a}$ & $133,5 b$ \\
\hline \multirow[t]{2}{*}{ NS } & $15 a$ & $7,9 a$ & $172,2 \mathrm{ab}$ \\
\hline & \multicolumn{3}{|c|}{----------BRS Tumucumaque--------- } \\
\hline IN & $12,9 a b$ & $8,0 \mathrm{a}$ & $151,4 \mathrm{ab}$ \\
\hline AN & $13,1 \mathrm{ab}$ & $7,9 a$ & $162,3 a b$ \\
\hline NS & $11,3 b$ & $8,1 \mathrm{a}$ & $175,5 a b$ \\
\hline$C \vee \%$ & 12.10 & 7.05 & 14.19 \\
\hline
\end{tabular}

As médias seguidas pela mesma letra não diferem estatisticamente entre si. Foi aplicado o Teste de Tukey ao nível de $5 \%$ de probabilidade.

A variedade Manteiguinha do nitrogênio do solo (NS) e adubação apresentou valores maiores de diâmetro nitrogenada (AN). A cultivar IPA 207 de caule quando inoculado (IN) seguido apresentou valores maiores de diâmetro 
de caule quando utilizou apenas o nitrogênio do solo (NS), seguido da inoculação (IN) e adubação nitrogenada (AN).

Em relação ao comprimento de plantas, a variedade Manteiguinha apresentou valores maiores quando utilizado adubação nitrogenada (AN), seguido da inoculação (IN) e nitrogênio do solo (NS). GUARESCHI et al. (2011) não encontrou diferenças significativas da inoculação de plantas de feijão em relação ao tratamento sem inoculação, e do tratamento sem inoculação em relação a adubação nitrogenada, para altura de plantas quando utilizou $B$. japonicum.

Para a cultivar IPA 207, maiores valores de comprimento de plantas foi obtido no tratamento quem houve inoculação $(I N)$, seguido do nitrogênio do solo (NS) e adubação nitrogenada (NA), no entanto esses para a produtividade de grãos o efeito dos tratamentos teve resultados inversos (Figura 1), em que a adubação nitrogenada apresentou maior produtividade de grãos, seguido do nitrogênio do solo e inoculação, isto pode estar relacionado a forma de utilização do nitrogênio pela planta, na qual se destinou a produção de grãos.

A cultivar BRS Tumucumaque apresentou maiores valores de comprimento de planta quando se utilizou apenas o nitrogênio do solo (NS), seguido da adubação nitrogenada (AN) e inoculação (IN). Silva (2015) não encontrou diferenças significativas para altura de plantas e diâmetro do caule em feijão-caupi quando utilizado a adubação nitrogenada em relação à inoculação. Apesar da inoculação não apresentar maior comprimento de plantas quando inoculado, esta apresentou maior produtividade quando inoculada (Figura 1).

As cultivares IPA 207 e BRS Tumucumaque não diferiram estatisticamente entre si quanto a produtividade, e os tratamentos também não tiveram diferenças significativas. A variedade regional Manteiguinha apresentou menores valores de produtividade dentre os tipos de feijão-caupi testados, esta apresentou 
valores maiores de produtividade no tratamento em que se aplicou a adubação nitrogenada, no entanto, não diferiu estatisticamente. A cultivar IPA 207 apresentou valores inferiores de produtividade quando se usou inoculante, apresentando valores maiores no tratamento em que se utilizou adubação nitrogenada, respostas semelhantes à variedade Manteiguinha, no entanto esta não diferiu estatisticamente dos demais tratamentos (inoculante e nitrogênio do solo). Ao contrário das demais, a cultivar
BRS Tumucumaque apresentou melhores resultados quando submetidos ao tratamento com inoculante, mostrando que a fixação biológica de nitrogênio se mostrou mais eficiente nesta cultivar, contribuindo para melhor incremento na produtividade de grãos (Figura 1), apesar de não significante a 5 $\%$ de probabilidade. GUALTER et al. (2008) não encontrou diferenças significativas na produtividade de feijãocaupi quando utilizou estipe do gênero Bradyrhizobium.

Figura 1. Produção média da variedade Manteiguinha e das cultivares IPA 207 e BRS Tumucumaque sob o efeito dos tratamentos: Inoculação, adubação nitrogenada e nitrogênio do solo.

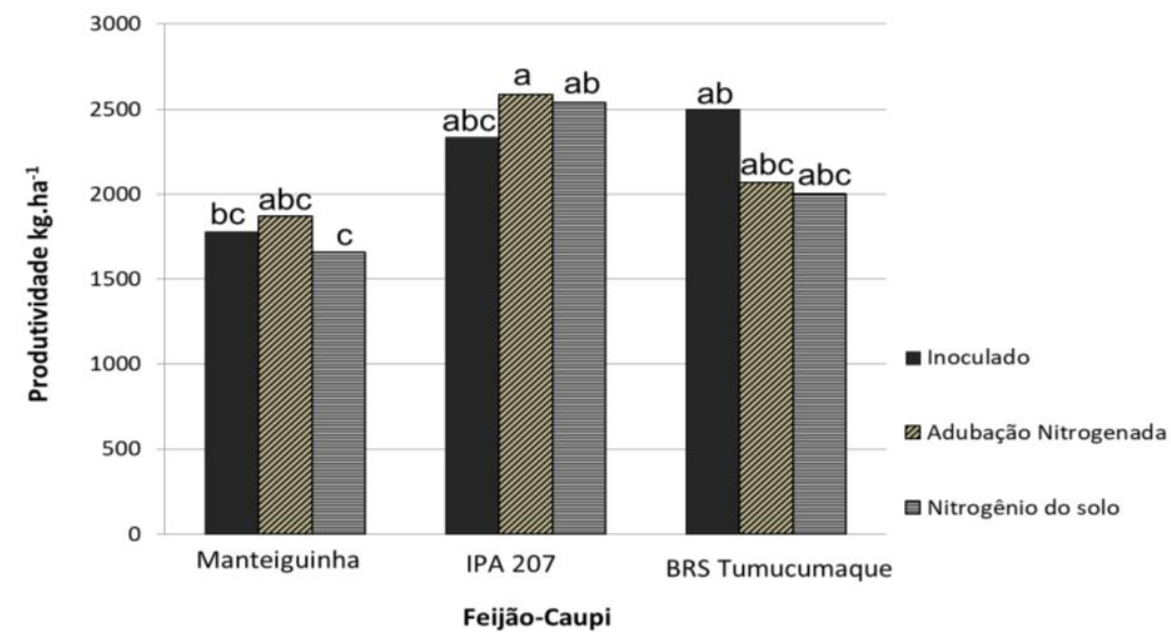

Fonte: Elaborado pelo autor.

As médias seguidas pela mesma letra não diferem estatisticamente entre si. Foi aplicado

- Teste de Tukey ao nível de 5\% de probabilidade. $\mathrm{CV} \%=17,28 \mathrm{dms}=773,43$. 
O potencial produtivo das cultivares em casa de vegetação se mostraram satisfatórios quando comparados com outros trabalhos realizados. Em estudo com a cultivar BRS Tumucumaque no ano de 2010 em Rio Preto da Eva, estado do Amazonas, foi constatado produtividade de $1395 \mathrm{~kg} \mathrm{ha-1}$ (OLIVEIRA et al., 2014), valores inferiores aos obtidos neste experimento na região de SantarémPA, o qual obteve-se produtividade máxima de 2499,9 kg ha-1 quando inoculado com estirpes de bactérias (Bradyrhizobium japonicum BR 3262), proporcionando incremento de $24,9 \%$.

A cultivar IPA 207 apresentou valor de produtividade máximo de 2586 kg ha ${ }^{-1}$ no tratamento com adubação nitrogenada, já no tratamento com inoculação da bactéria, houve redução na produtividade para $2333,6 \mathrm{~kg} \mathrm{ha}{ }^{-1}$, embora, os níveis de produtividade encontrados nestas condições experimentais terem sido maiores que os níveis encontrados por SANTOS et al. (2013) que obteve produtividade variando de 1292,0 kg ha-1 a 1374,70 kg ha-1. Isto demonstra a eficiência e viabilidade cultivo desta cultivar na região oeste paraense.

A variedade Manteiguinha foi a que apresentou menores valores de produtividade, apesar de não ser uma cultivar comercial, seu desempenho foi satisfatório vistos as médias encontradas em outros trabalhos, como os valores encontrados por OLIVEIRA et al. (1980), que obteve media de 1424 kg ha-1 em Belém-PA. Neste experimento os valores maiores de produtividade da variedade Manteiguinha foi o tratamento em que se utilizou a adubação nitrogenada, com média de 1869,5 kg ha-1.

Resultados positivos e negativos relacionados a produtividade de feijão-caupi foram encontrados por CHAGAS JUNIOR et al. (2010), no qual testaram cinco tipos de estirpes e encontraram produtividade baixas e altas em relação a testemunha. 0 feijão-caupi tem capacidade de associar-se com diversas espécies de bactérias fixadoras de nitrogênio, essa 
pouca especificidade pode ser prejudicial para o processo de fixação biológica de nutrientes, pois pode haver competição entre elas, se fazendo necessários estudos que busquem determinar estirpes mais eficientes.

Por meio deste estudo pode verificar-se que a inoculação com Bradyrhizobium japonicum (BR 3262) apresenta eficiência na elevação da produtividade da cultivar BRS Tumucumaque, e ineficiência quanto à produtividade da cultivar IPA 207.

\section{AGRADECIMENTOS}

À Universidade Federal do Oeste do Pará.

\section{REFERÊNCIAS}

ANDRADE， S. C. P.; VIEIRA, V. R.; MORAIS, H. F.; ALBUQUERQUE, E. M.; SANTOS, C. A. Estimativa de albedo, NDVI e Temperatura de Superfície no município de Santarém-PA. In: SIMPÓSIO BRASILEIRO DE SENSORIAMENTO REMOTO - SBSR, 16, 2013. Anais... Foz do Iguaçu, 2013.

ARAÚJO, C. L. de.; GUALTER, R. M. R. Caracterização morfofisiológica de bactérias nativas de solos do Cerrado isoladas de nódulos de feijão-caupi. Revista Biotemas, V. 30, n. 1, p. 25-35, 2017

CHAGAS JUNIOR, A. F.; RAHMEIER, W.; FIDELIS, R. R.; SANTOS, G, R.; CHAGAS, L. F. B. Eficiência agronômica de estirpes de rizóbio inoculadas em feijão-caupi no Cerrado, Gurupi-TO. Revista Ciência Agronômica, v. 41, n. 4, p. 709-714, out-dez, 2010

CRAVO, M. S.; SOUZA, B. D. L. Recomendações de adubação e calagem para o Estado do Pará. Belém: Embrapa Amazônia Oriental, 2007. p. 147-149.

GUALTER， R. M. R.; LEITE， L. F. C.; ARAÚJO, A. S. F.; ALCANTARA, R. M. C. M.; COSTA, D. B. Inoculação e adubação mineral em feijão-caupi: efeitos na Nodulação, crescimento e produtividade. Scientia Agraria, Curitiba, v. 9, n.4, p. 469-474, 2008.

GUARESCHI, R. F.; PERIN, A.; GAZOLLA, P. R.; ROCHA, A. C. Nodulação e crescimento vegetativo de feijão azuki submetido a inoculação e adubação nitrogenada. Global Science And Technology, v. 4, n. 3, p. $75-82$, set/dez. 2011.

HUNGRIA, M.; CAMPO, R. J.; MENDES, I. C. A importância do processo de fixação biológica do nitrogênio para a cultura da soja: componente essencial para a competitividade do produto brasileiro. Londrina: Embrapa soja, 2007. (Embrapa soja documentos, 283). 
OLIVEIRA, A. F. F; BARRIGA, R. H. M. P; FIGUEIREDO, F. J. C; SILVA, J. F. A. F; PONTE, M. T. Comportamento de Cultivares de Caupi na Região Amazônica. Belém, 1980. (EMBRAPA Centro de Pesquisa Agropecuária do Trópico Úmido, circular técnica 10).

SANTOS, J. F; CARDOSO, M. J; BASTOS, E. A. Desempenho Produtivo de Cultivares de Feijão-Caupi no Agreste Paraibano. In: CONGRESSO NACIONAL DE FEIJÃO-CAUPi, 3., 2013 Anais... Recife, PE, 2013. p. 3,

SANTOS, K. C.; UCHÔA, S. C. P.; MELO, V. F.; ALVES, J. M. A.; ROCHA, P. R. R.; XIMENES, C. K. S. Inoculação com Bradyrhizobium e adubação nitrogenada em feijão-caupi cultivado em diferentes solos. Revista Agro@mbiente On-line, Boa Vista, RR, v. 8, n. 3, p. 306-317, setembrodezembro, 2014.

SILVA, M. A. G.; GUIMARÃES JUNIOR, J. M.; NIHORAINY, F. C. S.; SANTOS, F. C. $V_{\text {.; }}$ UCKER, F. E. Caracterização pluviométrica de Santarém-Pa, Brasil. Revista Eletrônica de educação da Faculdade Araguaia, Goiânia, v.10, n. 10, p. 112-120, 2016.

SILVA, N. L. Feijão caupi inoculado com rizóbio e cultivado em solo com e sem compactação. Rondonópolis, 2015. 39 f. (Mestrado em Engenharia Agrícola)Universidade Federal De Mato Grosso, Instituto De Ciências Agrárias E Tecnológicas, Rondonópolis, 2015.

ZILLI, J. E.; VALICHESKI, R. R.; RUMJANEK, N. G.; SIMÕES-ARAÚJO, J.
L.; FREIRE FILHO, F. R.; NEVES, M. C. P. Eficiência simbiótica de estirpes de Bradyrhizobium isoladas de solo do Cerrado em caupi. Pesquisa Agropecuária Brasileira, Brasília, v. 41, n. 5, p.811-818, maio 2006. 